Article

\title{
Particle Erosion Induced Phase Transformation of Different Matrix Microstructures of Powder Bed Fusion Ti-6Al-4V Alloy Flakes
}

\author{
Jun-Ren Zhao, Fei-Yi Hung * (D) and Truan-Sheng Lui \\ Department of Materials Science and Engineering, National Cheng Kung University, Tainan 701, Taiwan \\ * Correspondence: fyhung@mail.ncku.edu.tw; Tel.: +886-6-275-7575 (ext. 62950)
}

Received: 9 June 2019; Accepted: 26 June 2019; Published: 28 June 2019

\begin{abstract}
In this study, powder bed fusion Ti-6Al-4V alloy flake was subjected to heat treatment at $800{ }^{\circ} \mathrm{C}$ for $4 \mathrm{~h}$ for inducing the complete transformation of the $\alpha^{\prime}$ phase into the $\alpha+\beta$ phases. An erosion experiment with $450 \mu \mathrm{m}$ mean particle diameter of $\mathrm{Al}_{2} \mathrm{O}_{3}$ particles at a $90^{\circ}$ impact on both the as- powder bed fusion (PBF) Ti-6Al-4V and the $4-\mathrm{h} 800^{\circ} \mathrm{C}$ heat-treated specimens to clarify the particle erosion-induced phase transformation behavior and its effect on mechanical properties. Particle erosion-induced phase transformation to the $\alpha$ phase was observed on both the as-PBF Ti-6Al-4V and the heat-treated specimens. It brought about a sequential formation from the surface to the bottom: (1) a surface softened zone, (2) a hardened zone, and (3) a hardness stabilization zone. The as-PBF Ti-6Al-4V was positively eroded by erosion particles, decreasing strength and ductility. In the case of the heat-treated specimens, we found decreased strength yet an increased ductility.
\end{abstract}

Keywords: powder bed fusion (PBF); Ti-6Al-4V; erosion; phase transformation; tensile

\section{Introduction}

Titanium alloys are widely applied in environments susceptible to erosion, including blades, turbines, and desalination pipeline [1]. Among them, Ti-6Al-4V is the most representative among the $\alpha+\beta$ titanium alloys [2,3], which possesses excellent specific strength, fracture toughness, corrosion resistance, and bio-compatibility [4]. However, its low thermal conductivity and high reactivity features, which result in its poor machinability characteristics, make it difficult to undertake further exploitation [5]. In addition, specific heat treatment operations are generally required due to the heat hardening phenomena during the cutting process. Additive manufacturing (AM) technology possesses great characteristics as a new manufacturing technique that is able to lower the cost and reduce energy consumption as well, solving current problems in the fabrication of Ti-6Al-4V and producing a near net shape component [6-8]. Powder bed fusion (PBF) process which uses metal powders as a raw material is a type of additive manufacturing (AM) technology. During PBF, metal powders are melted in a specified area with a high-energy laser beam, then it is rapidly solidified at a high cooling rate [9-13], resulting in its possessing the martensitic $\alpha^{\prime}$ phases, which differs from the classical $\alpha+\beta$ phase structure. In the meantime, the phase transformation takes place when the material is heated.

Erosion wear often results in the failure of mechanical devices and components. Therefore, it is necessary to study the erosion wear phenomenon. However, there are a significant number of research articles on the mechanical properties of PBF Ti-6Al-4V [14,15], but few on the erosion wear. And the little research about the wear of titanium alloys, most of them focusing on water droplet erosion [16-19], not on solid particle erosion. The particle erosion articles had also mainly focused on erosion resistance [20-22], instead of the particle erosion-induced phase transformation. According to our previous researches $[23,24]$, particle erosion wear is able to induce phase transformation and affects 
the erosion rate. Therefore, we want to clarify the erosion-induced phase transformation mechanism and its effect on the tensile mechanical properties in this study. In this part, erosion particles were used to positively erode the as-PBF Ti-6Al-4V and the heat-treated specimens at a $90^{\circ}$ impact angle. The results have significant reference value for relevant industry applications.

\section{Experimental Procedure}

The PBF process parameters used in this study are shown in Table 1. The specimens were fabricated by using an EOS M290 400 W machine (EOS, Krailling, Germany) in an inert gas (argon) atmosphere. The chemical composition values of as-PBF Ti-6Al-4V measured by the Inductively Coupled Plasma Mass Spectrometry (ICP-MS, THERMO-ELEMENT XR, Alberta, Canada) are shown in Table 2. The specimens were removed from support by electrical discharge machining (EDM) wire cutting and did not go through any post-treatment before the implemented tests. The as-PBF Ti-6Al-4V specimen was labeled AS. The heat-treated specimen was held for $4 \mathrm{~h}$ in a tubular furnace in an argon atmosphere at $800^{\circ} \mathrm{C}$ and was subjected to air cooling (labeled HT).

Table 1. Process parameters used for the powder bed fusion (PBF) process.

\begin{tabular}{cc}
\hline Process parameters & Value \\
\hline Laser power $(\mathrm{W})$ & 170 \\
\hline Scanning velocity $(\mathrm{mm} / \mathrm{s})$ & 800 \\
\hline Layer thickness $(\mu \mathrm{m})$ & 30 \\
\hline Laser radius $(\mu \mathrm{m})$ & 35 \\
\hline Particle size $(\mu \mathrm{m})$ & $15-45$ \\
\hline
\end{tabular}

Table 2. PBF Ti-6Al-4V chemical composition (wt.\%).

\begin{tabular}{cccccccc}
\hline $\mathbf{A l}$ & $\mathbf{V}$ & $\mathbf{F e}$ & $\mathbf{O}$ & $\mathbf{C}$ & $\mathbf{N}$ & $\mathbf{H}$ & $\mathbf{T i}$ \\
\hline 6.13 & 3.80 & 0.30 & 0.20 & 0.08 & 0.05 & 0.01 & Bal. \\
\hline
\end{tabular}

The erosion test equipment is shown in Figure 1. We used irregular $\mathrm{Al}_{2} \mathrm{O}_{3}$ particles for erosion test, which had an average particle size of $450 \mu \mathrm{m}$. The particle SEM morphology is shown in Figure 2. The specimens were polished with SiC paper (from \#80 to \#1000) to remove the oxidized layer and were soaked in acetone for ultrasonic cleaning before the erosion test. Two hundred grams of the erosion particles were used under a compressed air flow of $3 \mathrm{~kg} / \mathrm{cm}^{2}$ (0.29 MPa). During the erosion test, the AS and HT specimens were eroded at a $90^{\circ}$ impact angle to investigate the particle erosion induced phase transformation phenomenon.
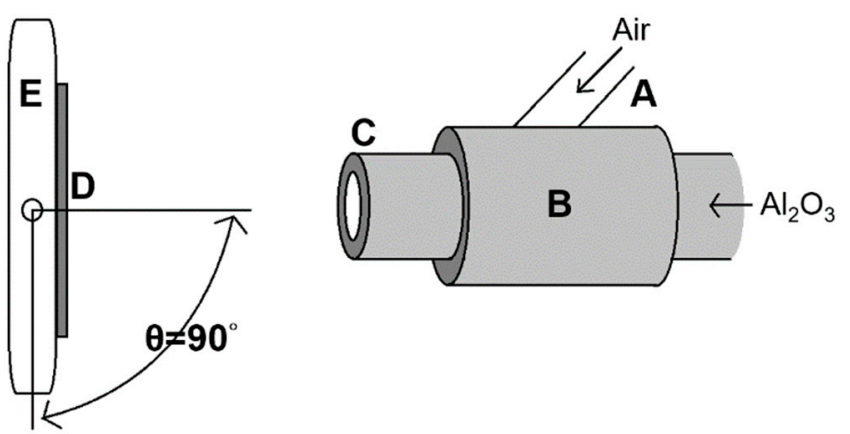

Figure 1. The equipment for particle erosion test. (A: compressed air flow; B: erosion particle $\left(\mathrm{Al}_{2} \mathrm{O}_{3}\right.$ particles) supplier; C: erodent nozzle; D: specimen; E: specimen holder; $\theta$ : $90^{\circ}$ impact angle). 


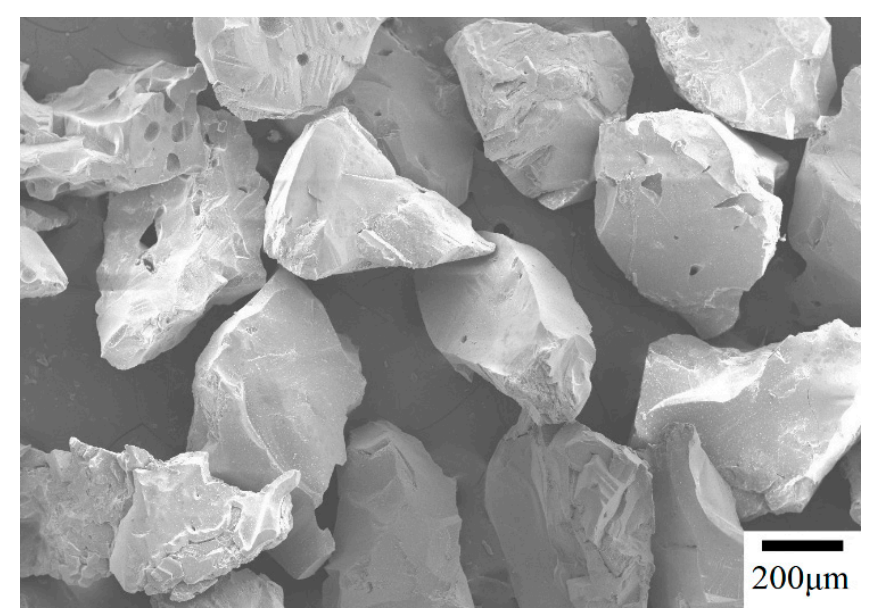

Figure 2. SEM image of $\mathrm{Al}_{2} \mathrm{O}_{3}$ erosion particles morphology and size.

After the erosion test, the specimens were polished with \#80 to \#4000 SiC paper, placed into 1 and $0.3 \mu \mathrm{m} \mathrm{Al}_{2} \mathrm{O}_{3}$ aqueous solution, and then transferred to a $0.04 \mu \mathrm{m} \mathrm{SiO}_{2}$ polishing solution. Finally, they were etched by Keller's reagent ( $\left.1 \mathrm{~mL} \mathrm{HF}+1.5 \mathrm{~mL} \mathrm{HCL}+2.5 \mathrm{~mL} \mathrm{HNO}_{3}+95 \mathrm{~mL} \mathrm{H}_{2} \mathrm{O}\right)$. Optical microscopy (OM, OLYMPUS BX41M-LED, Tokyo, Japan) and transmission electron microscopy (TEM; Tecnai F20 G2, EFI, Hillsboro, OR, USA) were used to examine the subsurface microstructure of the erosion specimens.

For analyzing the structural difference between AS and HT specimens before and after erosion, X-ray diffractometry (XRD, Bruker AXS GmbH, Karlsruhe, Germany) was used. To analyze the hardness distribution along the longitudinal direction after the erosion, the hardness measurements were evaluated by the Vickers hardness test (Shimadzu HMV-2000L, SHIMADZU, Kyoto, Japan).

The dimensions of the PBF Ti-6Al-4V tensile specimen are shown in Figure 3. The normal direction (ND) of the specimen was set parallel to the laser direction. The direction vertical to the laser direction was called the side direction (SD). A universal testing machine (HT-8336, Hung Ta, Taichung, Taiwan) was used to perform the tensile test. The crosshead speed was chosen $1 \mathrm{~mm} / \mathrm{min}$, corresponding to the initial strain rate of $18.33 \times 10^{-4} \mathrm{~s}^{-1}$. The parallel section of both the AS and the HT specimens eroded by $200 \mathrm{~g}$ of particles under a compressed air flow of $3 \mathrm{~kg} / \mathrm{cm}^{2}(0.29 \mathrm{MPa})$ at the $90^{\circ}$ impact angle.

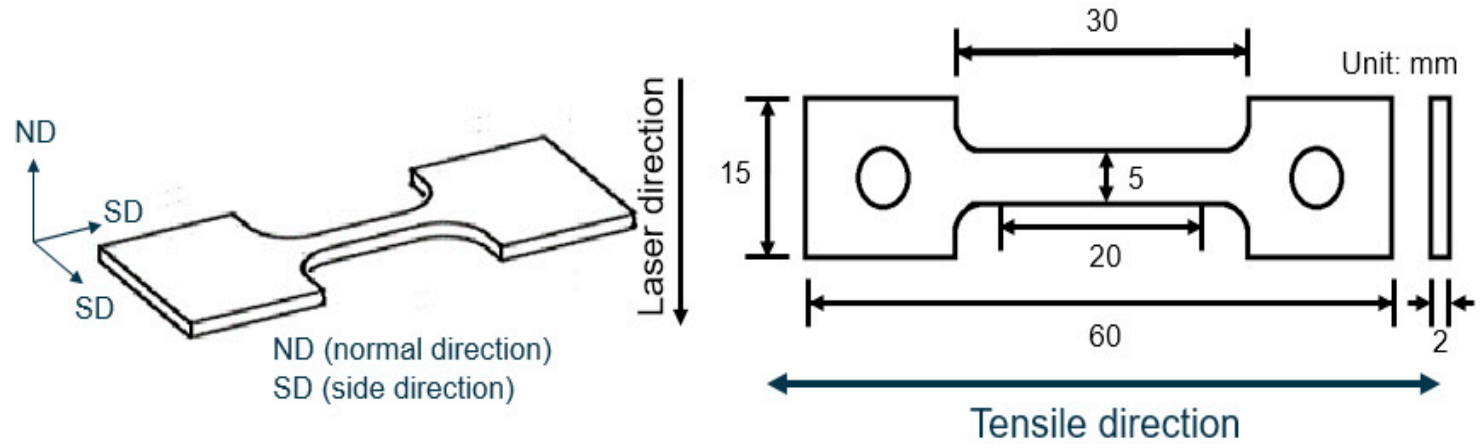

Figure 3. Dimensions of the tensile specimen.

To analyze the influence of the particle erosion induced phase transformation on both the AS and HT specimens, a tensile test was performed at room temperature. There were at least three specimens during each test, for which the tensile test results were averaged. 


\section{Results and Discussion}

\subsection{Erosion Induced Phase Transformation Behavior}

Figure $4 \mathrm{a}$ shows the SD microstructure of the as-PBF Ti-6Al-4V (AS). There is a needle-like structure in AS matrix. The interpretation, according to the literature [11,12], is the extremely high temperature gradient during quenching, which transformed the $\beta$ phases completely into a needle-like martensitic $\alpha^{\prime}$ phase. Figure $4 \mathrm{~b}$ shows the SD microstructure of the HT specimen (which was subjected to heat treatment at $800{ }^{\circ} \mathrm{C}$ for $4 \mathrm{~h}$ ). The $\alpha^{\prime}$ phases were completely transformed into continuous lamellar $\alpha+\beta$ phases, as shown in our previous research [22].
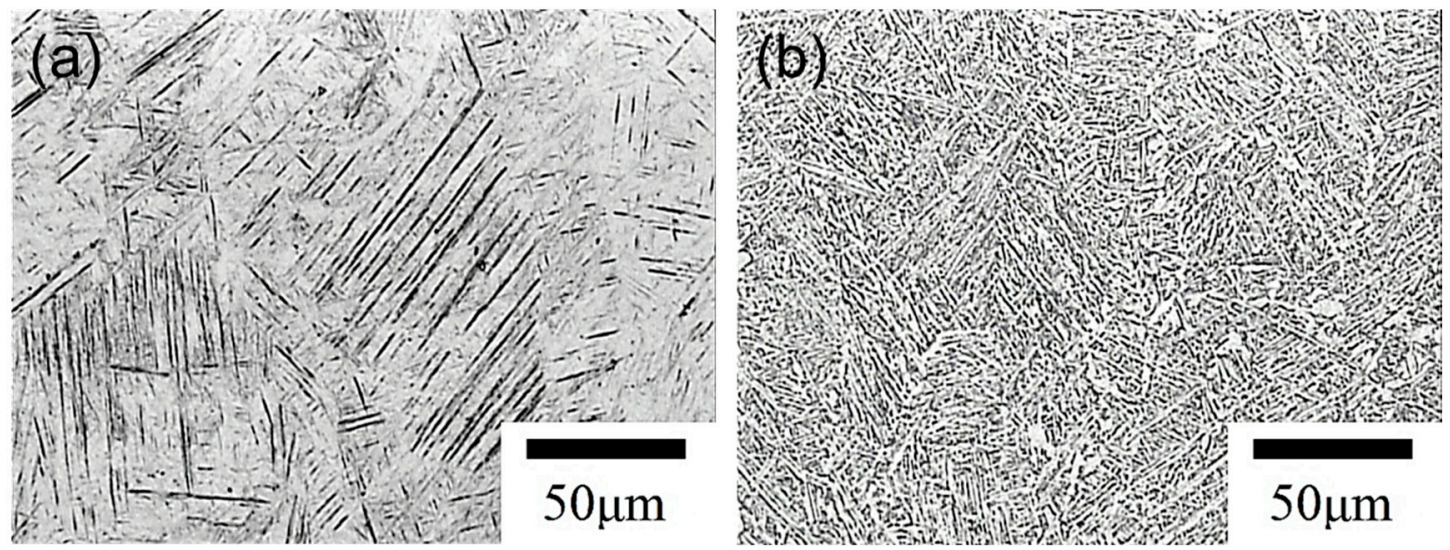

Figure 4. Microstructures of side direction (SD): (a) AS (b) HT.

The subsurface morphology of AS at $90^{\circ}$ impact angle is shown in Figure 5a. We can observe positively eroded pits formed by erosion particles. There was no obvious relationship between the pits and the needle-like structure. Similar pits can be seen on the subsurface morphology of HT at $90^{\circ}$ impact angle (Figure 5b), but the interface of the pits is almost located on the white $\alpha$ phase among the lamellar $\alpha+\beta$ phases. There is no obvious change in optical microscopy (OM) microstructures on both AS and HT specimens after erosion.
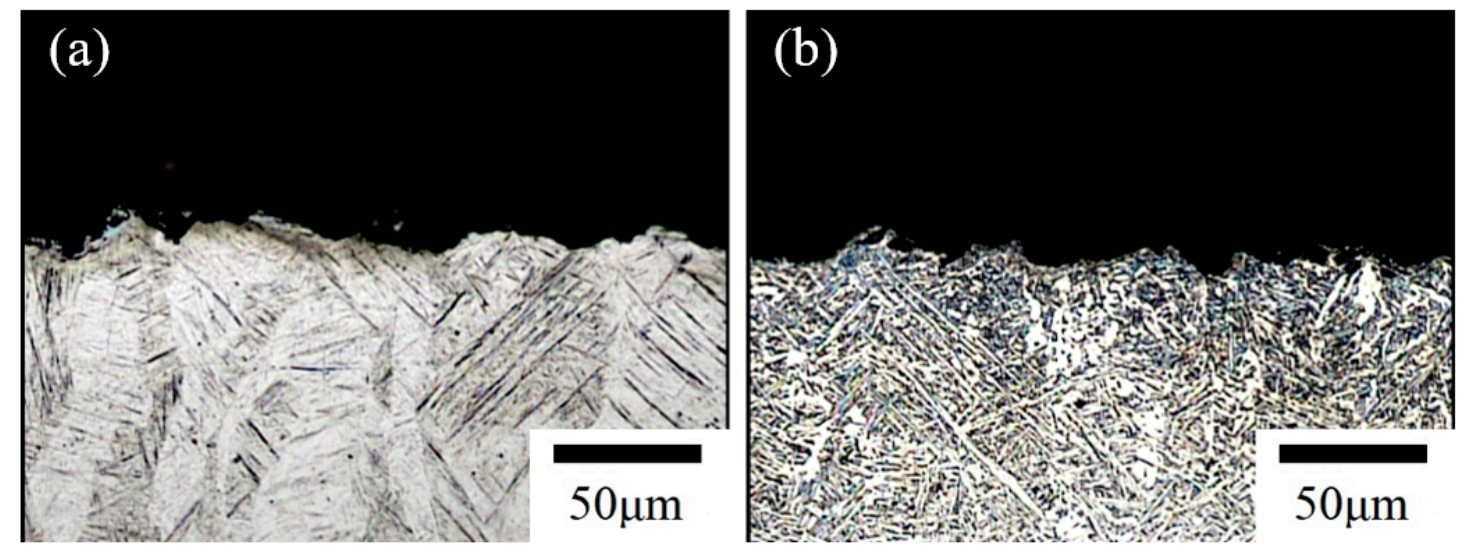

Figure 5. Subsurface morphology at $90^{\circ}$ impact angle: (a) AS (b) HT.

However, the microstructural difference between AS and HT specimens before and after erosion can be obtained through TEM observation. After being positively eroded by endured $90^{\circ}$ impact angle, these two specimens are labeled as ASE and HTE, respectively. The $\alpha^{\prime}$ phase of AS specimen, as shown in Figure $6 a, b$, shows the selected area electron diffraction (SAED) pattern of $\alpha^{\prime}$ phase. A $+\beta$ phase comes up in HT specimen (Figure 6c), the thickness of $\alpha$ phase is approximately $1.5 \mu \mathrm{m}$. The SAED pattern of $\beta$ phase is shown in Figure 6d. Figure 7 shows TEM images of AS and HT specimens after 
erosion. In short, the microstructures after erosion are completely changed. Figure $7 \mathrm{~b}, \mathrm{~d}$ illustrate the well-defined ring pattern indicating fine grains within the region selected.
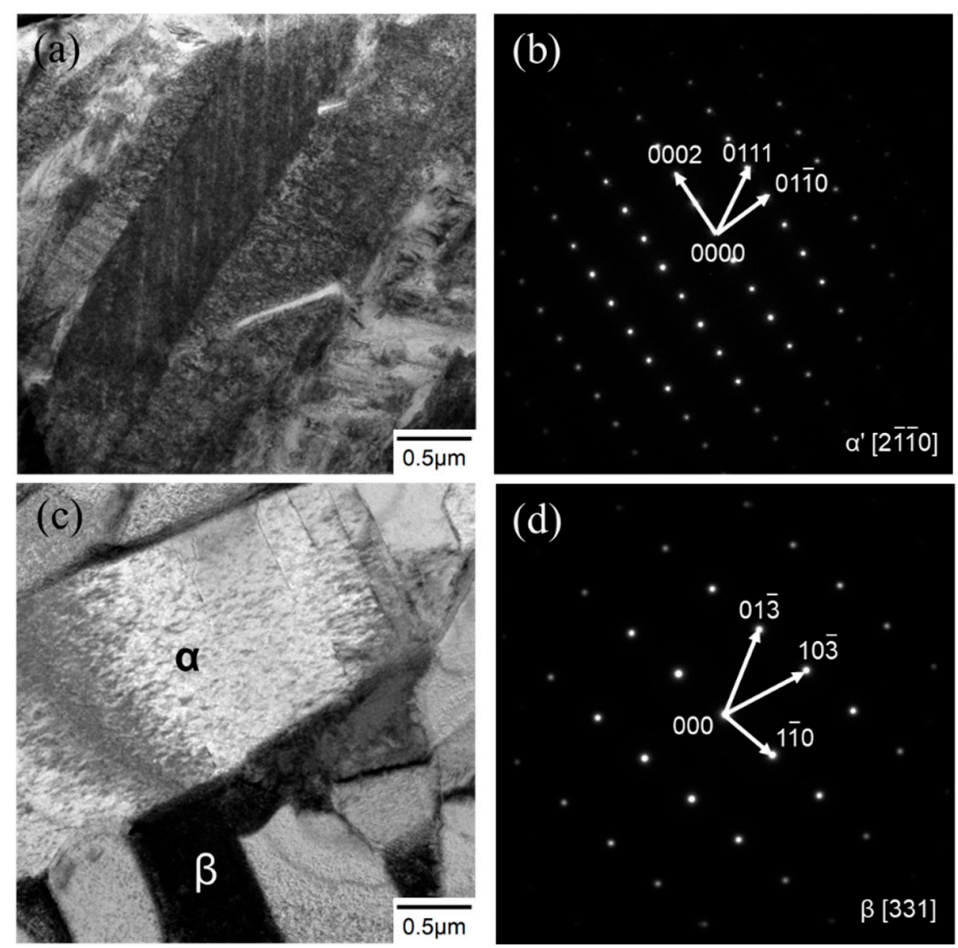

Figure 6. TEM images of specimens before erosion: (a) $\alpha^{\prime}$ phase microstructure of AS, (b) SAED pattern of $\alpha^{\prime}$ phase, (c) $\alpha+\beta$ phase microstructure of HT, and (d) selected area electron diffraction (SAED) pattern of $\alpha+\beta$ phase.
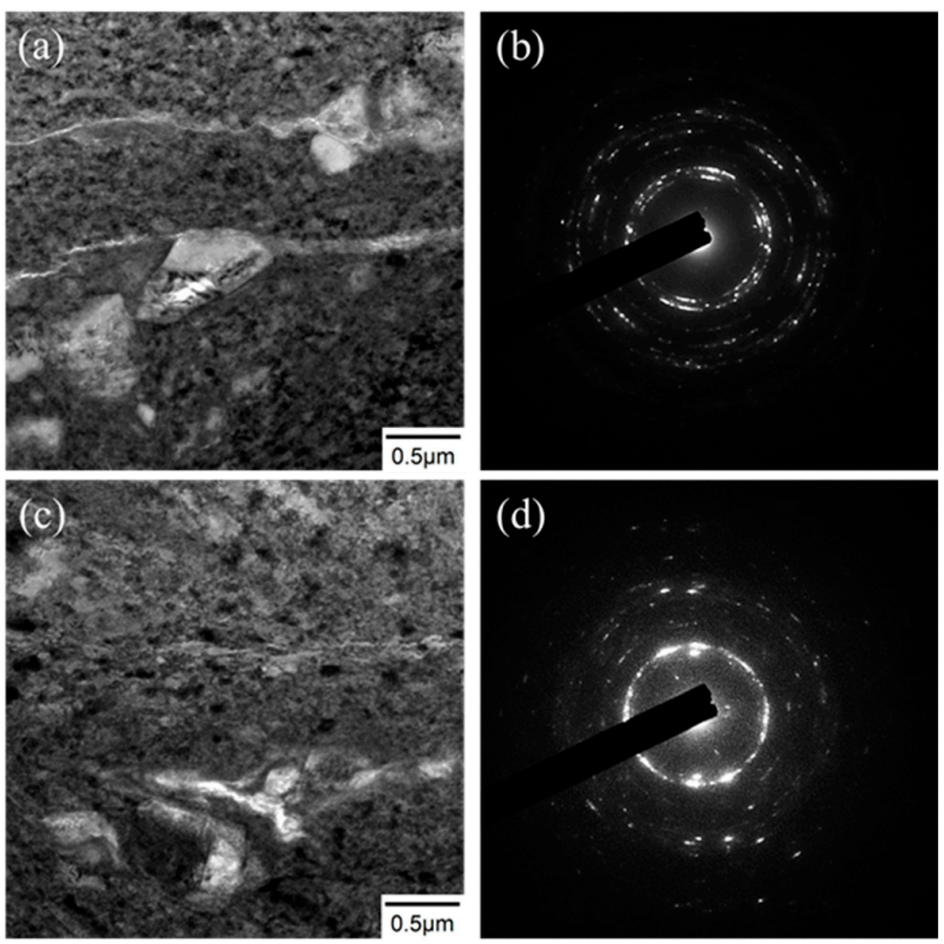

Figure 7. TEM images of specimens after erosion: (a) ASE, (b) SAED pattern of ASE, (c) HTE, and (d) SAED pattern of HTE. 
Figure 8 displays the XRD diffraction analysis of the AS, and HT after the positively eroded endured $90^{\circ}$ impact angle. Note the respective label changes to ASE and HTE. Both Figure 8 and the previous reports $[13,22,25,26]$ suggest the following observation about the presence of the $\alpha / \alpha^{\prime}$ and the $\beta$ peaks in HT: when an AS specimen is heated to $800^{\circ} \mathrm{C}$, the $\alpha^{\prime}$ phases disappear, and then transforms to continuous lamellar $\alpha+\beta$ phases. Notably, ASE and HTE had two more peaks (210) and (202) than AS and HT. It was confirmed that the martensitic $\alpha^{\prime}$ phase was generated when the temperature gradient grew extremely high during the cooling process. The $\alpha^{\prime}$ phase has completely transformed into the $\alpha+\beta$ phases during heating to and maintaining at $800{ }^{\circ} \mathrm{C}$. Thereby, it is suggested that both of ASE and HTE generated a new $\alpha$ phase after the $\mathrm{Al}_{2} \mathrm{O}_{3}$ particle erosion-induced phase transformation. The new generation phase ratios of ASE and HTE were $9.2 \%$ and $7.4 \%$, respectively, which indicated that more $\alpha$ phase formation was induced in AS than in HT.

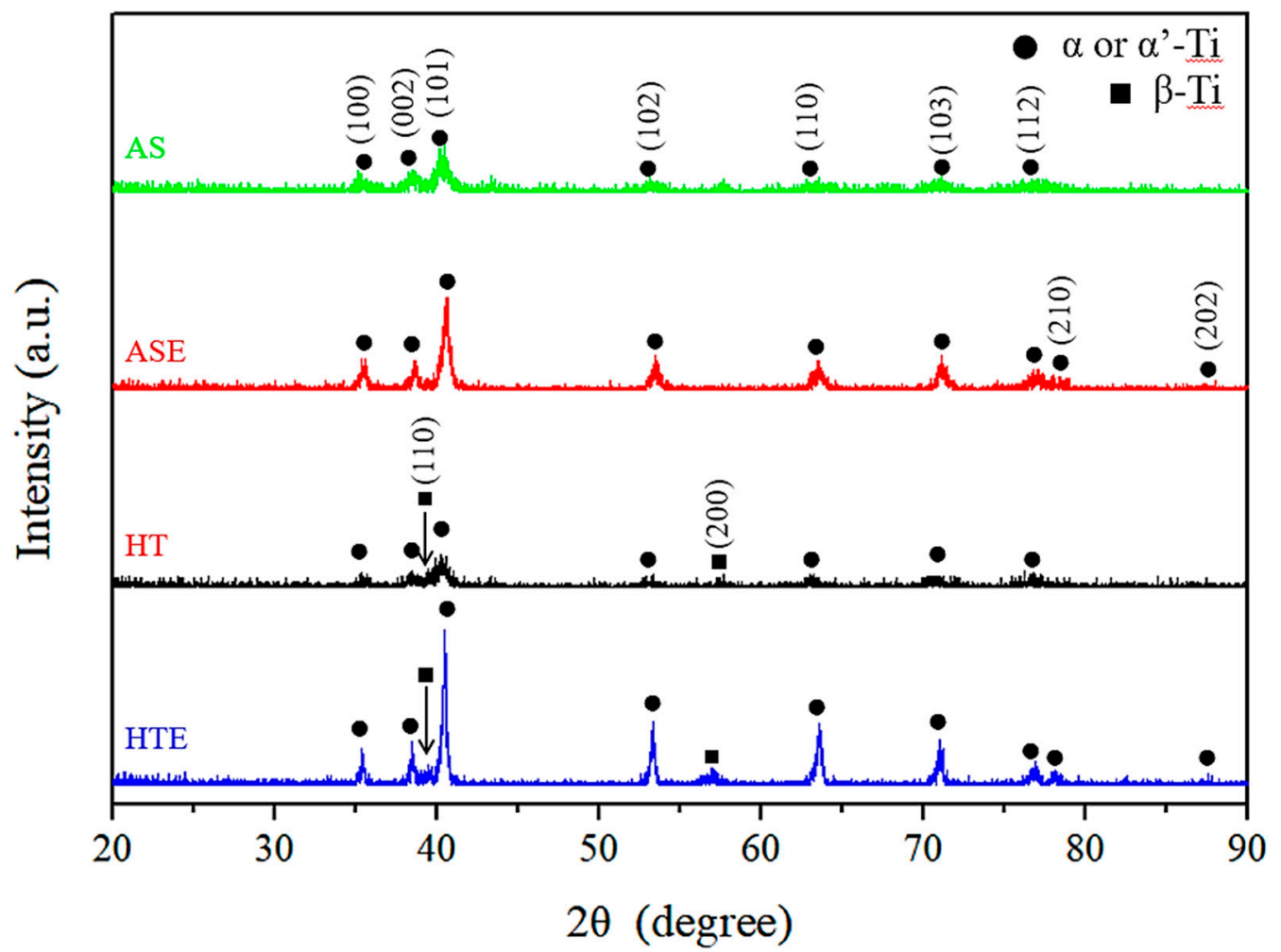

Figure 8. X-ray diffraction pattern of AS, ASE, HT, and HTE.

The hardness distribution along the longitudinal direction of ASE and HTE is shown in Figure 9. The full erosion subsurface can be divided into three zones: (1) the softened zone of the outermost surface, (2) the hardened zone below the softened zone, and (3) the hardness stabilization zone down to the bottom. The softened and hardened zone thicknesses for ASE were $150 \mu \mathrm{m}$ and $300 \mu \mathrm{m}$, respectively. The Vickers hardness of the three zones were 420 to $430 \mathrm{HV}, 500$ to $540 \mathrm{HV}$, and 450 to $480 \mathrm{HV}$, respectively. Similarly, the softened and hardened zone thicknesses for HTE were $250 \mu \mathrm{m}$ and $200 \mu \mathrm{m}$, respectively. The Vickers hardness of the three zones were 360 to $380 \mathrm{HV}, 430$ to $460 \mathrm{HV}$, and 410 to $420 \mathrm{HV}$, respectively. The decline in the hardness of the near-surface zone can be attributed to a compound effect: The AS material was transformed from a hard martensitic $\alpha^{\prime}$ phase to a soft $\alpha$ phase, and the positive erosion produced a thermosoftened layer. According to previous reports [22,27], the hardness of the double phase Ti-6Al-4V alloy decreases with the rate of the $\alpha$ phase, which can be attributed to a new $\alpha$ phase formation and the thermal compound effect caused by particle impact [23]. The formation of the hardened zone can be attributed to positive erosion caused by the downward pressure of the specimen surface. 


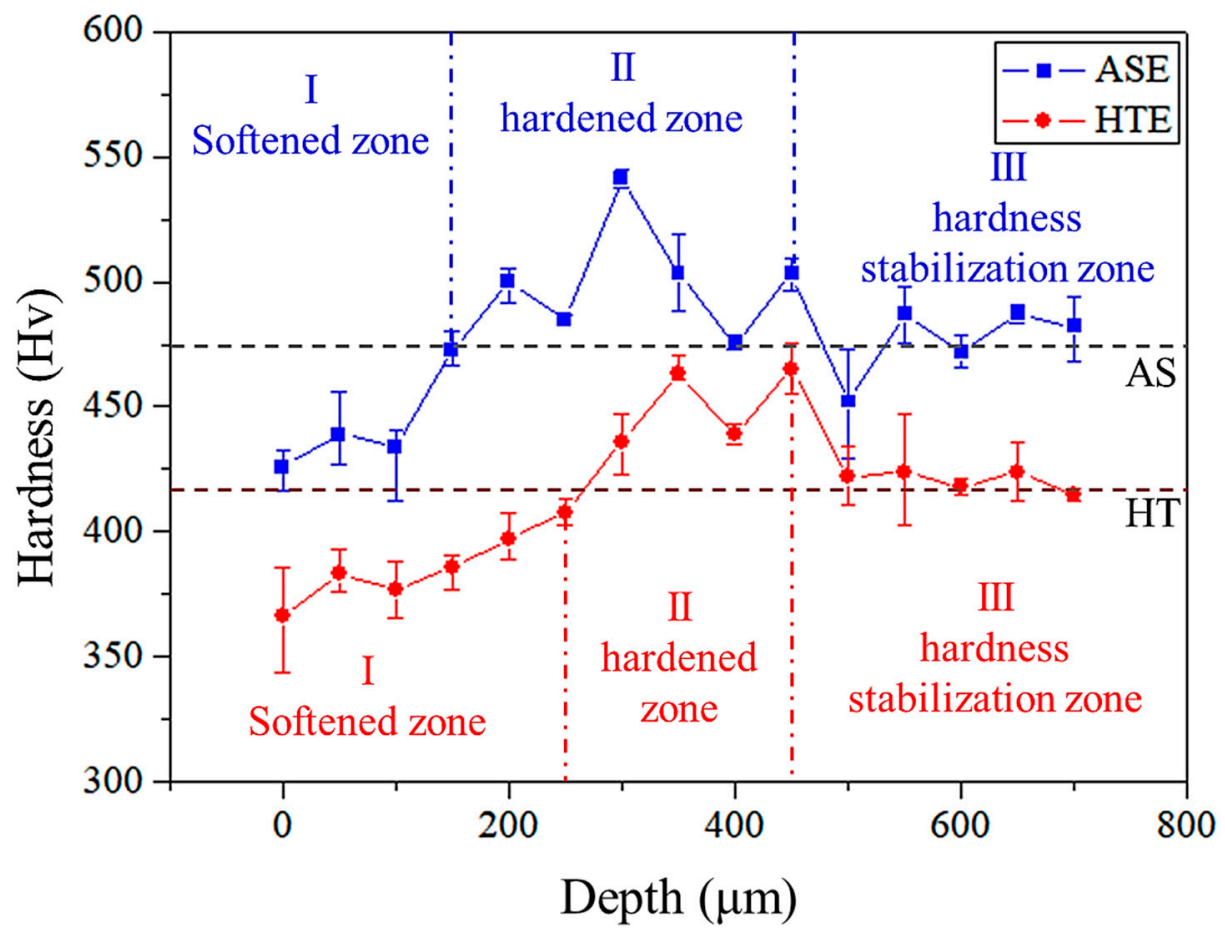

Figure 9. Hardness distribution of ASE and HTE in the longitudinal direction.

In summary, the positive erosion (by $\mathrm{Al}_{2} \mathrm{O}_{3}$ particles) induced a phase transformation for both $\mathrm{AS}$ and HT toward generating a soft $\alpha$ phase. At the same time, the softened zone with a thickness of 150 to $250 \mu \mathrm{m}$ was formed by the thermal effect of the positively eroded particles, and the hardened zone below the softened zone was formed by a squeeze effect, as shown in Figure 10. Because the AS specimen had a higher rate of the $\alpha$ phase induced by eroded particles, the hardness difference between the softened and the hardened zones grew larger than that for the HT specimen.

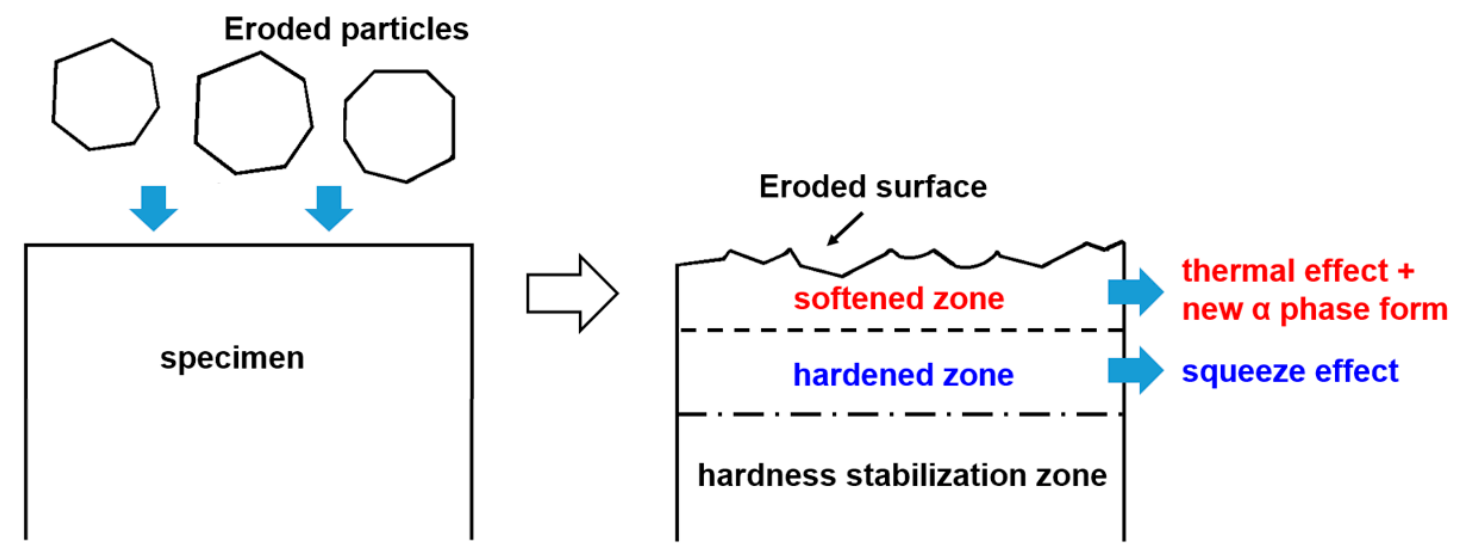

Figure 10. Schematic diagram of particle erosion induced phase transformation.

\subsection{Influence of Erosion Induced Phase Transformation on Mechanical Properties}

Figure 11 shows the stress-strain curve of AS and HT before and after positive erosion at a $90^{\circ}$ impact angle. The tensile strength significantly reduced, and Young's modulus increased after the needle-like $\alpha^{\prime}$ phase of PBF Ti-6Al-4V completely transformed into the $\alpha+\beta$ phase. The stress-strain curve moved toward the left after the parallel sections of AS and HT eroded by particles. Young's modulus changed from the original $111 \pm 5$ GPa (AS) and $133 \pm 6 \mathrm{GPa}(\mathrm{HT})$ to $130 \pm 4 \mathrm{GPa}$ (ASE) and $127 \pm 5 \mathrm{GPa}$ (HTE). It means that the stiffness of AS improved after the erosion-induced phase transformation, but the stiffness of HT did not change after the erosion. 


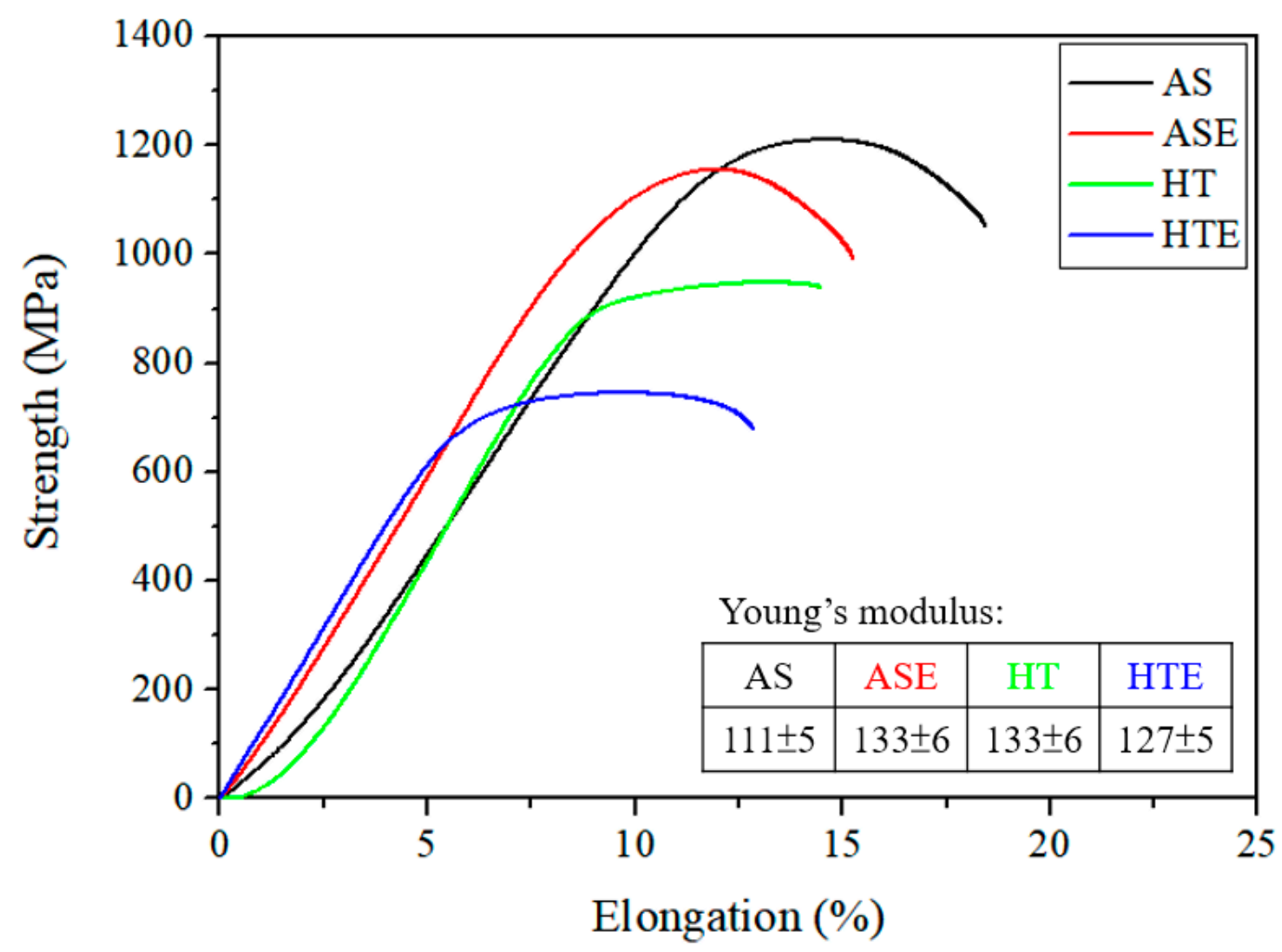

Figure 11. Stress-strain curve of AS, ASE, HT, and HTE.

The tensile mechanical proprieties of AS and HT before and after positive erosion at a $90^{\circ}$ impact angle are shown in Figure 12. After heat treatment, the tensile strength of HT became lower than that of AS. This underlines that the phase transformation decreases the tensile strength. After the erosion-induced phase transformation, the tensile strength of ASE and HTE became lower than that of the original AS and HT specimens. This underlines that the generated of the $\alpha$ phase by eroded particles and the change of hardness lead to a decreased of tensile strength; Ductility had a different trend. The ductility of ASE was slightly lower than that of AS. However, the ductility of HTE became higher than that of HT.

To clarify the effect of erosion-induced phase transformation on tensile mechanical properties, the tensile fracture surfaces after erosion were observed. We found no obvious shrinkage phenomenon in ASE and HTE as tensile test specimens. The macroscopic fracture morphology of ASE is flatter, while HTE shows an oblique line of fracture, see Figure 13.

Figure 14a,b show the morphology of the tensile fracture surfaces of AS and HT, respectively. It can be observed that there are Dimpled ductility structures in both specimens, indicating that both the needle-like $\alpha^{\prime}$ phase and the lamellar $\alpha+\beta$ phases contribute ductile fractures. Similarly, the morphology of the softened zone tensile fracture surface of ASE includes an almost dimpled ductility structure (Figure 14c). The difference between ASE and AS and HT specimens is that many particles are located in the dimpled ductility structure. Energy-dispersive X-ray spectroscopy (EDS) indicated a titanium-aluminum phase, with the atomic percentage being 88:12, as listed in Table 3. 

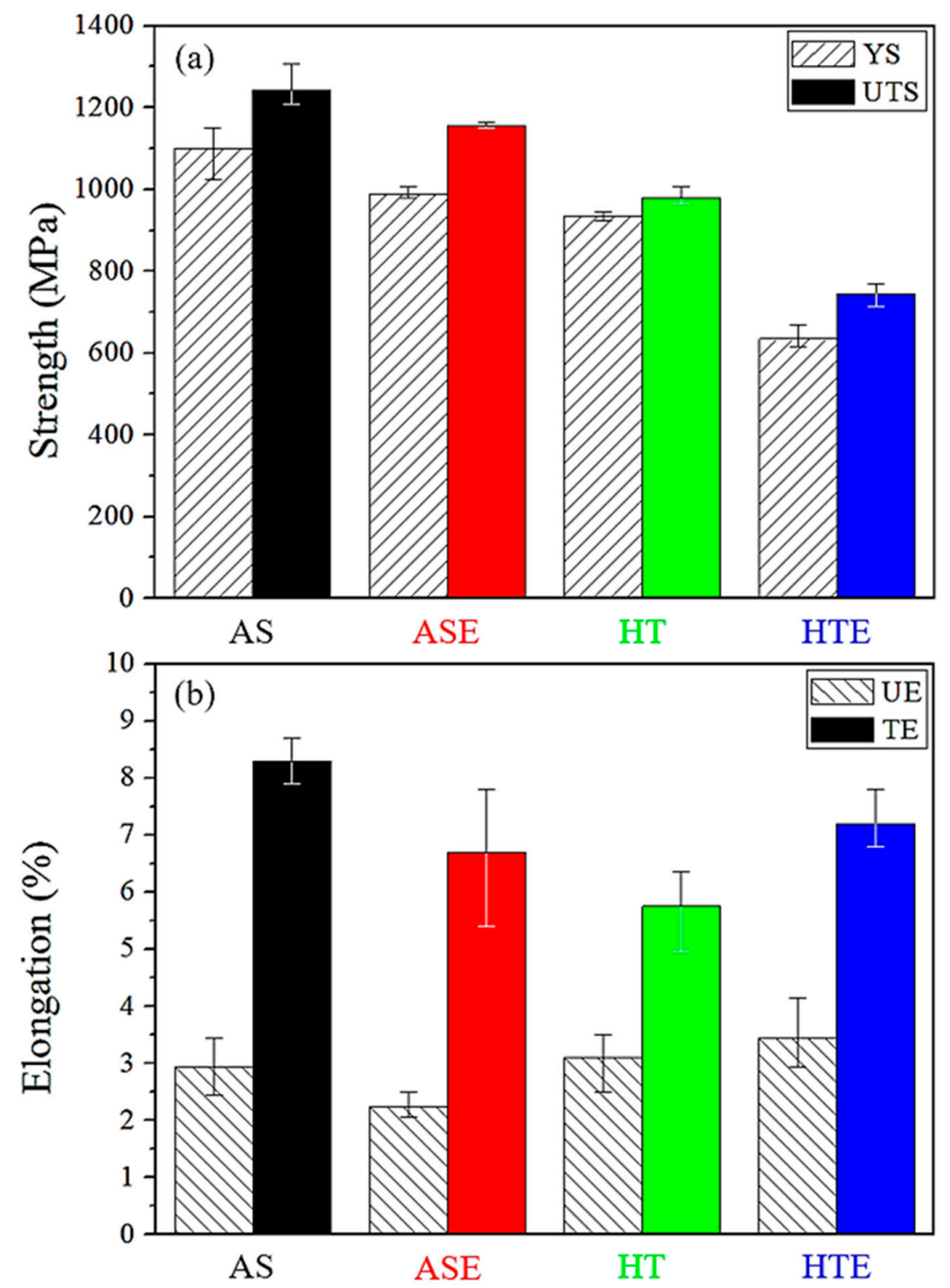

Figure 12. Tensile properties of AS, ASE, HT, and HTE: (a) strength (b) ductility.

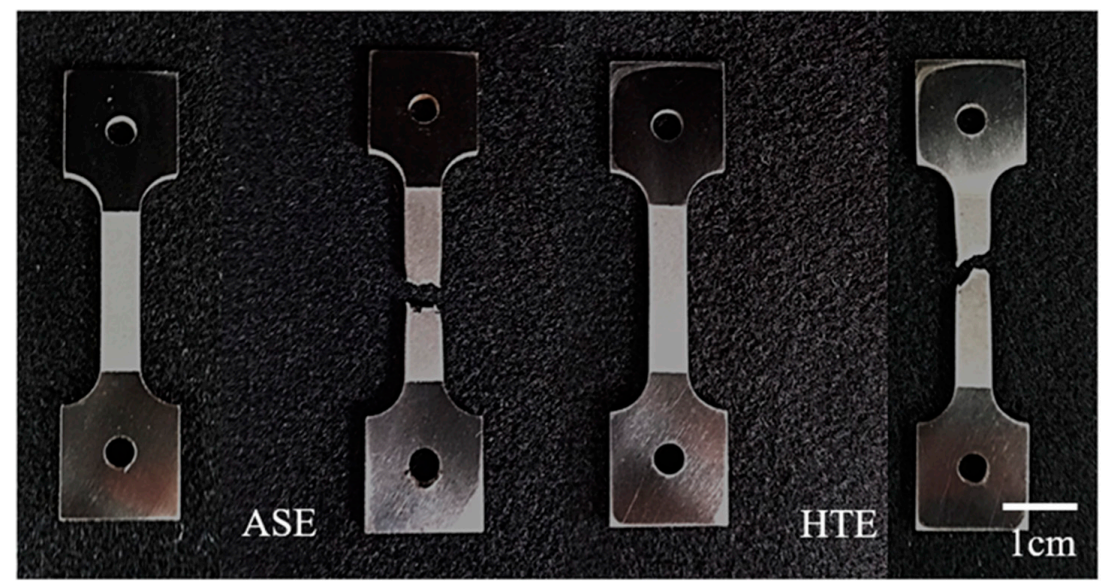

Figure 13. Macroscopic morphology photographs of ASE and HTE before and after tensile test. 

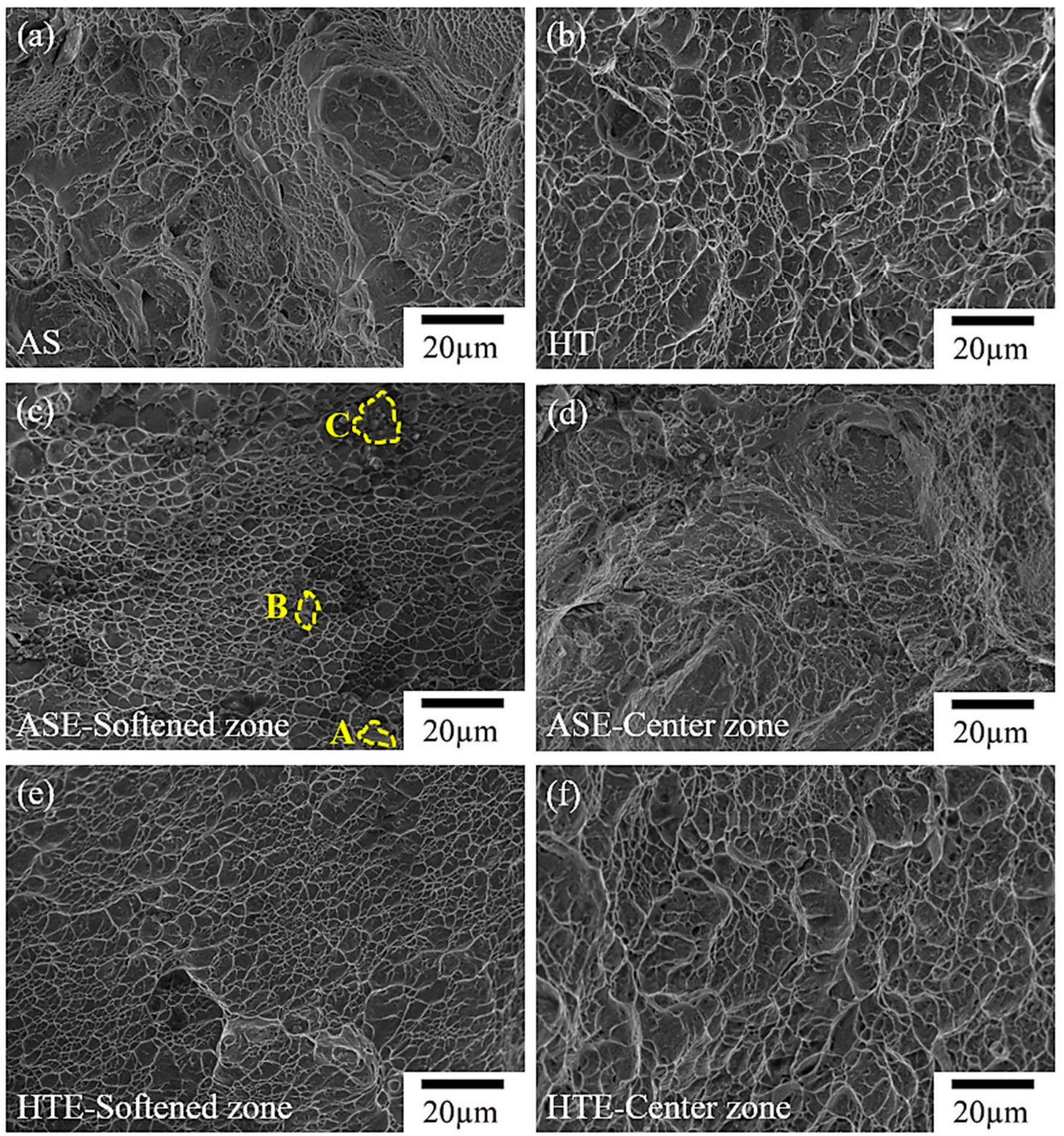

Figure 14. Morphology of tensile fracture surfaces: (a) AS (b) HT (c) ASE softened zone (d) ASE center zone (e) HTE softened zone and (f) HTE center zone.

Table 3. Phase of particles analyzed by EDS.

\begin{tabular}{cccccc}
\hline \multicolumn{1}{c}{ A } & \multicolumn{2}{c}{ B } & \multicolumn{2}{c}{ C } \\
\hline Element & At\% & Element & At\% & Element & At\% \\
\hline $\mathrm{Ti}$ & 12.38 & $\mathrm{Ti}$ & 11.26 & $\mathrm{Ti}$ & 11.35 \\
\hline $\mathrm{Al}$ & 86.18 & $\mathrm{Al}$ & 87.76 & $\mathrm{Al}$ & 88.06 \\
\hline $\mathrm{V}$ & 1.44 & $\mathrm{~V}$ & 0.98 & $\mathrm{~V}$ & 0.59 \\
\hline
\end{tabular}

Figure 14d displays the morphology of the middle zone tensile fracture surface of ASE. The observed cleavage facets show a different fracture morphology from the softened zone. The tensile fracture surface of HTE is almost the dimpled structure, but there are no titanium-aluminum phase particles in the softened zone of HTE, as shown in Figure 14.

Figure $14 \mathrm{f}$ shows the morphology of the middle zone tensile fracture surface of THE. Even if cleavage facets could also be observed, the almost dimpled ductility structures dominated. 
Figure 15 is the schematic diagram of the erosion particle impact tensile specimen. When erosion particles eroded, the erosion-induced phase transformation occurred, resulting in decreased strength on both the AS and HT specimens. It is inferred that as the number of erosion particles rises, the tensile strength gradually decreased. In ductility, there are different trends on the AS and HT specimens. After the erosion-induced phase transformation, AS showed titanium-aluminum phase particles in dimpled ductility structures in the softened zone, resulting in a slight decline of strength and ductility. In contrast, there were no titanium-aluminum phase particles in the softened zone of HT, resulting in decreased strength but increased ductility. There are three reasons why the ASE ductility was lower than that of AS, and the HTE ductility was higher than that of HT: 1. Particle erosion-induced phase transformation, 2. the different depth of the softened zone, and 3. the titanium-aluminum phase particles appearing in the softened zone. The $\alpha$ phase was generated by erosion induced phase transformation in the surface softened zone. The titanium-aluminum phase particles present only in the softened zone of ASE formed the $\alpha$ phase.
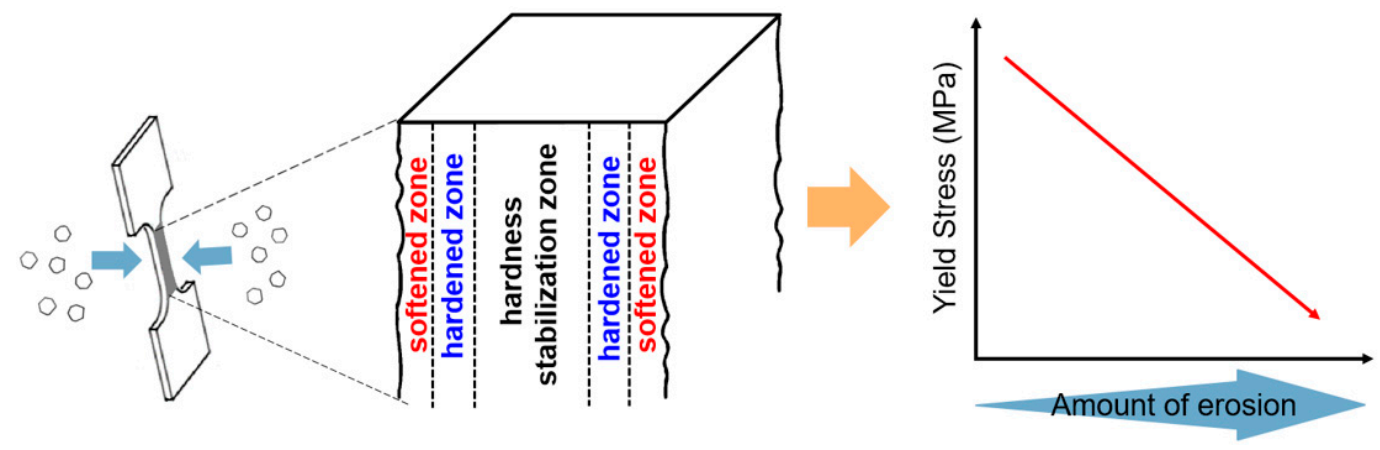

Figure 15. Schematic diagram of the erosion particle impact specimen leading to a decrease in strength.

\section{Conclusions}

A new $\alpha$ phase was generated by the as-PBF Ti- $6 \mathrm{Al}-4 \mathrm{~V}$ specimen and the heat-treated specimen after the erosion. The heat affected the composite effect of $\mathrm{Al}_{2} \mathrm{O}_{3}$ particle erosion, and the erosion surface adopted a serial formation: softened zone, hardened zone, and hardness stabilization zone. The ratio of the new $\alpha$ phase induced by particle erosion in ASE became higher than that in HTE, resulting in a difference of hardness between the softened and the hardened zones.

After the PBF Ti-6Al-4V was subjected to a heat treatment at $800{ }^{\circ} \mathrm{C}$ for $4 \mathrm{~h}$, the phase transformation $\alpha^{\prime} \alpha+\beta$ resulted in a decrease of the strength. The mechanical properties of both the as-PBF Ti-6Al-4V and the heat-treated specimens were affected by particle erosion-induced phase transformation. The strength and the ductility of the ASE test specimens became lower than those of AS, and titanium-aluminum phase particles were observed in the softened zone. There were no titanium-aluminum phase particles found in HTE. Compared with the HT test specimen, the strength decreased, but the ductility increased.

Author Contributions: Methodology, J.-R.Z.; investigation, J.-R.Z.; data curation, J.-R.Z.; writing-original draft preparation, J.-R.Z.; writing-review and editing, F.-Y.H. and T.-S.L.; supervision, F.-Y.H. and T.-S.L.

Funding: This research received no external funding.

Acknowledgments: The authors are grateful to The Instrument Center of National Cheng Kung University and the Ministry of Science and Technology of Taiwan (Grant No. MOST 107-2221-E-006-012-MY2) for their financial support for this research.

Conflicts of Interest: The authors declare no conflict of interest. 


\section{References}

1. Shi, Y.; Liu, Y.; Li, X.; Zhang, Y. Effect of Ultrasonic Surface Rolling Process on Solid Particles Erosion Performance of Ti-6Al-4V. IOP Conf. Ser. Mater. Sci. Eng. 2018, 394. [CrossRef]

2. Ahmadi, M.; Karpat, Y.; Acar, O.; Kalay, Y.E. Microstructure effects on process outputs in micro scale milling of heat treated Ti6Al4V titanium alloys. J. Mater. Process. Technol. 2018, 252, 333-347. [CrossRef]

3. Oh, S.T.; Woo, K.D.; Kim, J.H.; Kwak, S.M. The Effect of Al and V on Microstructure and Transformation of $\beta$ Phase during Solution Treatments of Cast Ti-6Al-4V Alloy. Korean J. Met. Mater. 2017, 55, 150-155.

4. Tao, P.; Li, H.X.; Huang, B.Y.; Hu, Q.D.; Gong, S.L.; Xu, Q.Y. Tensile behavior of Ti-6Al-4V alloy fabricated by selective laser melting: effects of microstructures and as-built surface quality. Chin. Foundry 2018, 15, 243-252. [CrossRef]

5. Dutta, B.; Froes, F.H.S. The Additive Manufacturing (AM) of titanium alloys. Met. Powder Rep. 2017, 72, 1-11. [CrossRef]

6. Trevisan, F.; Calignano, F.; Aversa, A.; Marchese, G.; Lombardi, M.; Biamino, S.; Ugues, D.; Manfredi, D. Additive manufacturing of titanium alloys in the biomedical field: Processes, properties and applications. J. Appl. Biomater. Funct. Mater. 2017, in press. [CrossRef]

7. Saboori, A.; Gallo, D.; Biamino, S.; Fino, P.; Lombardi, M. An Overview of Additive Manufacturing of Titanium Components by Directed Energy Deposition: Microstructure and Mechanical Properties. Appl. Sci. 2017, 7, 883. [CrossRef]

8. Saboori, A.; Tusacciu, S.; Busatto, M.; Lai, M.; Biamino, S.; Fino, P.; Lombardi, M. Production of Single Tracks of Ti-6Al-4V by Directed Energy Deposition to Determine the Layer Thickness for Multilayer Deposition. J. Vis. Exp. 2018, 133, 1-10. [CrossRef]

9. Yadroitsev, I.; Krakhmalev, P.; Yadroitsava, I. Selective laser melting of Ti6Al4V alloy for biomedical applications: Temperature monitoring and microstructural evolution. J. Alloys Compd. 2014, 583, 404-409. [CrossRef]

10. Song, B.; Dong, S.; Liao, H.; Coddet, C. Process parameter selection for selective laser melting of Ti6Al4V based on temperature distribution simulation and experimental sintering. Int. J. Adv. Manuf. Technol. 2012, 61, 967-974. [CrossRef]

11. Kelly, C.N.; Evans, N.T.; Irvin, C.W.; Chapman, S.C.; Gall, K.; Safranski, D.L. The effect of surface topography and porosity on the tensile fatigue of 3D printed Ti-6Al-4V fabricated by selective laser melting. Mater. Sci. Eng. C 2019, 98, 726-736. [CrossRef] [PubMed]

12. Sun, J.; Yang, Y.; Wang, D. Parametric optimization of selective laser melting for forming Ti6Al4V samples by Taguchi method. Opt. Laser Technol. 2013, 49, 118-124. [CrossRef]

13. Song, B.; Dong, S.; Zhang, B.; Liao, H.; Coddet, C. Effects of processing parameters on microstructure and mechanical property of selective laser melted Ti6Al4V. Mater. Des. 2012, 35, 120-125. [CrossRef]

14. Kim, Y.K.; Park, S.H.; Yu, J.H.; AlMangour, B.; Lee, K.A. Improvement in the high-temperature creep properties via heat treatment of Ti-6Al-4V alloy manufactured by selective laser melting. Mater. Sci. Eng. A 2018, 715, 33-40. [CrossRef]

15. Shunmugavel, M.; Polishetty, A.; Goldberg, M.; Singh, R.; Littlefair, G. A comparative study of mechanical properties and machinability of wrought and additive manufactured (selective laser melting) titanium alloy -Ti-6Al-4V. Rapid Prototyp. J. 2017, 23, 1051-1056. [CrossRef]

16. Gujba, A.K.; Hackel, L.; Kevorkov, D.; Medraj, M. Water droplet erosion behaviour of Ti-6Al-4V and mechanisms of material damage at the early and advanced stages. Wear 2016, 358-359, 109-122. [CrossRef]

17. Kamkar, N.; Bridier, F.; Jedrzejowski, P.; Bocher, P. Water droplet impact erosion damage initiation in forged Ti-6Al-4V. Wear 2015, 322-323, 192-202. [CrossRef]

18. Kamkar, N.; Bridier, F.; Bocher, P.; Jedrzejowski, P. Water droplet erosion mechanisms in rolled Ti-6Al-4V. Wear 2013, 301, 442-448. [CrossRef]

19. Mahdipoor, M.S.; Kevorkov, D.; Jedrzejowski, P.; Medraj, M. Water droplet erosion behavior of gas nitride Ti6Al4V. Surf. Coat. Technol. 2016, 292, 78-89. [CrossRef]

20. Pieters, R.; Liu, S. Shortlisted Particle Erosion Resistance of Laser Nitrided Ti-6Al-4V. Surf. Eng. 2001, 17, 159-162. [CrossRef]

21. Sahoo, R.; Jha, B.B.; Sahoo, T.K.; Mantry, S. Effect of Volume Fraction of Primary Alpha Phase on Solid Particle Erosion Behavior of Ti-6Al-4V Alloy. Tribol. Trans. 2015, 58, 1105-1118. [CrossRef] 
22. Zhao, J.R.; Hung, F.Y.; Lui, T.S.; Wu, Y.L. The Relationship of Fracture Mechanism between High Temperature Tensile Mechanical Properties and Particle Erosion Resistance of Selective Laser Melting Ti-6Al-4V Alloy. Metals 2019, 9, 501. [CrossRef]

23. Liou, J.W.; Lui, T.S.; Chen, L.H. $\mathrm{SiO}_{2}$ particle erosion of A356.2 aluminum alloy and the related microstructural changes. Wear 1997, 211, 169-176. [CrossRef]

24. Hung, F.Y.; Chen, L.H.; Lui, T.S. Phase Transformation of an Austempered Ductile Iron during an Erosion Process. Mater. Trans. 2004, 45, 2981-2986. [CrossRef]

25. Thijs, L.; Verhaeghe, F.; Craeghs, T.; Humbeeck, J.V. A study of the microstructural evolution during selective laser melting of Ti-6Al-4V. Acta Mater. 2010, 58, 3303-3312. [CrossRef]

26. Do, D.K.; Li, P. The effect of laser energy input on the microstructure, physical and mechanical properties of Ti-6Al-4V alloys by selective laser melting. Virtual Phys. Prototyp. 2016, 11, 41-47. [CrossRef]

27. Sahoo, R.; Jha, B.B.; Sahoo, T.K.; Sahoo, D. Effect of Microstructural Variation on Dry Sliding Wear Behavior of Ti-6Al-4V Alloy. J. Mater. Eng. Perform. 2014, 23, 2092-2102. [CrossRef]

(C) 2019 by the authors. Licensee MDPI, Basel, Switzerland. This article is an open access article distributed under the terms and conditions of the Creative Commons Attribution (CC BY) license (http://creativecommons.org/licenses/by/4.0/). 